\title{
Um passeio pelo Moskovsky Metropoliten
}

Luciano Spinelli

Paris Descartes Sorbonne ${ }^{1}$

Esta narrativa apresenta um ponto de vista sobre o metrô de Moscou. Partilhando sensaçôes individuais de uma experiência subterrânea coletiva, fotos, som e texto são resquícios da subjetivação de um viajante na atmosfera metroviária.

Palavras chave: foto-etnografia, deriva urbana, metrô, Russia.

$A$ travessei a fronteira russa em Terehova, num ônibus cheio de letões vindos de Riga. Sendo o único passageiro que não falava russo, fui parado na imigração. Contei com a ajuda de um viajante poliglota para explicar à funcionária da aduana que, desde 2010, os brasileiros podem entrar na Rússia sem visto. Meia hora depois voltei ao ônibus, em posse de uma cerveja Báltika e de um sanduíche de pão preto. Sacolejei por doze horas até chegar a Moscou.

Desembarquei ao lado da estação Rizhskaya e entrei no metrô. Lá, em agosto de 2004, separatistas chechenos detonaram uma bomba que matou 10 pessoas e feriu outras 50 . Senti pela primeira vez os ares comunistas. Pilares monumentais, lustres e mármores. Escadas rolantes de 126 metros com 740 degraus. Policiais por toda parte e ex-bolcheviques vendendo tickets. Alguns funcionários a esmo, esperando a vida passar em frente à televisão que transmite imagens das câmeras do circuito interno. Essa foi a primeira impressão que tive do mundo profundamente subterrâneo que tinha ido conhecer.

Saí na estação Pushkinskaya, um amigo me esperava. Passei duas semanas em Moscou experimentando detalhes da vida ordinária. Provei a kroshka kartoshka - batata recheada vendida em quiosques espalhados por toda a cidade, tomei vodka sogurcami - vodca com picles, andei de bombila - taxi ilegal, em geral velhos Lada ou Volga dirigidos por imigrantes. Mas, encantado por trens, aviões, gruas e outras construções metálicas que se movem, o que mais me impressionou foi o metrô. Nos primeiros dias, percorri aleatoriamente as estações contidas dentro do círculo

$1 \quad$ Centre d'Études sur l'Actuel et le Quotidien. 
formado pela linha 5 marrom. Perder-se foi inevitavelmente fácil quando os nomes das estações e todas as outras indicações estão escritas em alfabeto cirílico, algumas em alfabeto latino, em todo caso, sempre em russo.

Disposto a mudar meu método de visita metropolitana, tentei instrumentalizar algumas das intuições de Guy Debord. Parti à deriva, vivendo de forma lúdica esse espaço que interliga segmentos citadinos, percorrido apressadamente pelo moscovita. Após horas de vagabundagem, criei um vínculo afetivo com esse labirinto iluminado artificialmente. Aprendi a dizer ostorozhno, dveri zakryvayutsa - atenção ao fechamento das portas. Habituei-me a ouvir a voz masculina que anuncia as estações no sentido centro e a feminina no sentido bairro: convenção adotada em 1984 para ajudar na orientação dos cegos, mas interpretada por muitos como uma personificação do patrão que convoca ao trabalho e da esposa que chama de volta ao lar.

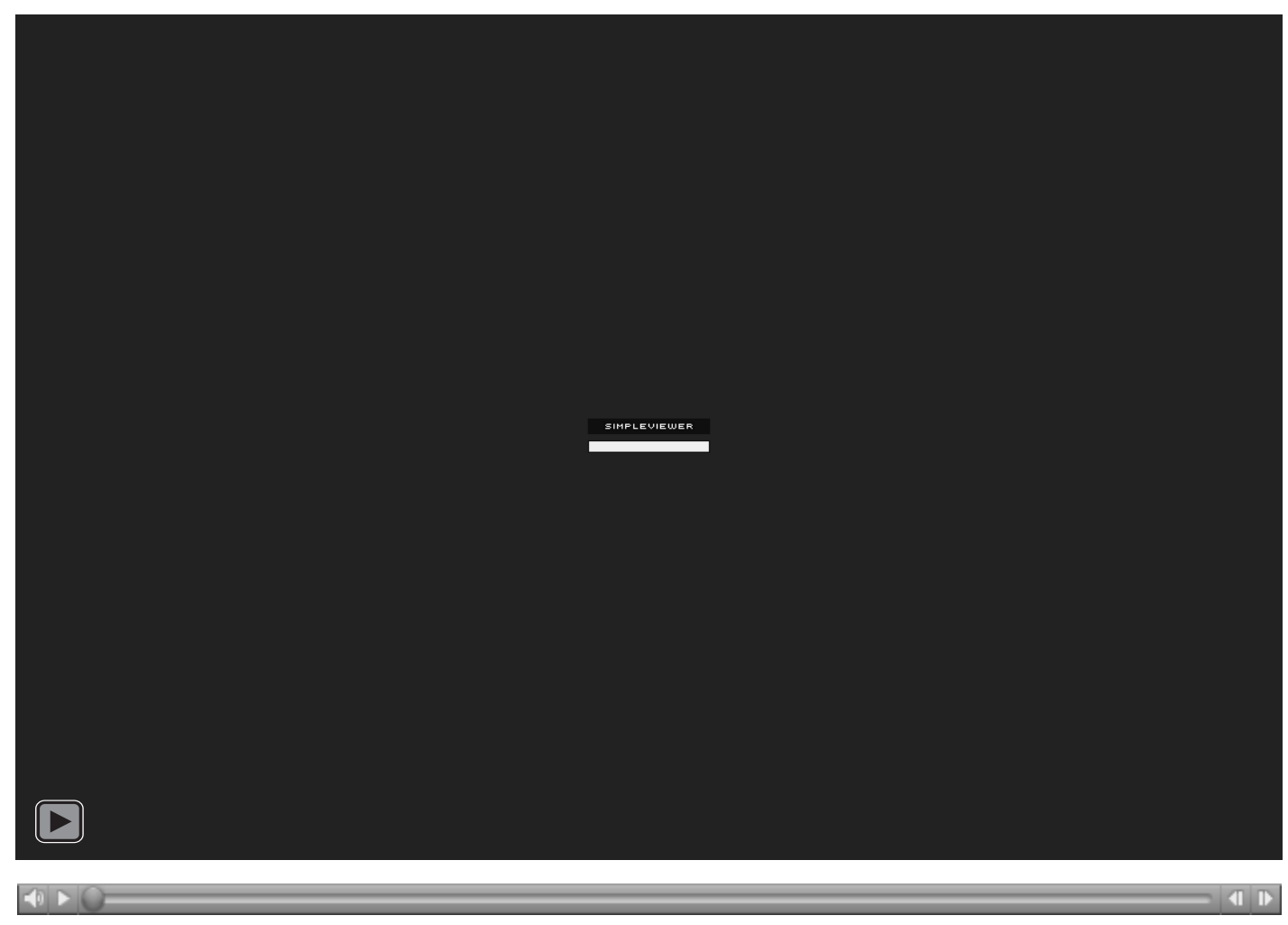

Já mais familiarizado com o mapa colorido do metrô, inevitavelmente esquemático e simplista, exercitei uma psicogeografia primitiva quando algumas estações passaram a me remeter a pontos já conhecidos da cidade. Percebi nas pessoas uma mudança de humor quando imersas no metrô: mais sérias, objetivas e determinadas. As interações afetivas pareciam dissimuladas, voltando a ser tecidas ao redor de uma cerveja, bebida ao ar livre, logo na saída da estação. Registrei uma cartografia subjetiva desse interstício urbano e de suas interações sociais em três rolos de Kodak Tmax 400 com uma Leica M6. Um exercício não exaustivo de estranhamento imagético dos ritmos subterrâneos começou quando, na primeira foto, descobri a ilegalidade da prática dentro do recinto em questão. Mas nem todos os seguranças fazem valer tal regra e gradualmente comecei a olhar pelo visor da câmera. Privilegiando horários matutinos e noturnos, com a estação mais vazia, senti o tipo de solidão que se abate especialmente nos habitantes das megalópoles. 
Usando o mobiliário das estações como tripé, fiz fotos possíveis, nem sempre nos ângulos desejados, tentando adequar o quadro à iluminação ambiente. Esse obstáculo técnico incitou à uma forma apropriativa do território, ditando uma inter-relação entre suporte, técnica e objeto fotografado. Com a câmera apoiada no corrimão da escada rolante, ou na janela de um trem em movimento, entrei no compasso da engrenagem metroviária. Durante esse processo assimilativo, a câmera fotográfica passou pela "incorporação dinâmica do objeto" assim como descrita por JeanPierre Warnier. Quando seu uso me passou despercebido, comecei a ser mais discreto, fotografando de forma espontânea, por vezes sem observar pelo visor do aparelho.

Por uma educação etnográfica do olhar, tentei revelar, assim como fiz com os negativos fotografados, uma forma de ver e mostrar o meio de transporte que mais carrega indícios da identidade moscovita. Deixei o tempo e as pessoas passarem em frente à câmera, obturador aberto. Elas em geral não interagiam com as fotos, imersas em suas próprias rotinas. As que notavam, portavam por vezes um olhar curioso, acenavam, vinham conversar. Falando no inglês que coube à situação, ouvi histórias sobre o Metrô 2, a decoração no estilo realista soviético e o hábito de acariciar o nariz da estátua em bronze de um cão para ter boa sorte. Esse primeiro me intrigou: um sistema secreto de túneis mais profundos que os do metrô para uso da elite nacional, que interligam o Kremlin, o edifício da antiga KGB (agora FSB), o aeroporto de Vnukovo-2 a uma cidade subterrânea em Ramenki com um bunker capaz de abrigar 10 mil pessoas em caso de guerra nuclear. As pessoas com as quais conversei sobre esse projeto me pareceram crédulas de sua existência, mesmo não tendo visto evidências concretas.

Não me detive na história das estações, mas já tinha lido sobre algumas delas. Por coincidência ou não, fiz as ultimas fotos do ensaio em Mayakovskaya. Lá, no inverno de 1941, quando Moscou estava cercada pelos Alemães durante a Segunda Guerra Mundial, Joseph Stalin instalou provisoriamente seu escritório na plataforma central e discursou para a população. Essa foi também a primeira estação do mundo a ter sua abóbada apoiada por apenas duas fileiras de pilares e não três. Passei um tempo descendo a escada rolante que leva ao cais, com profundidade de 33 metros para servir de abrigo em caso de bombardeio. Subi novamente, fotografei as pessoas, os lustres e alguns dos 24 mosaicos de Alexander Deyneka que compõem "o dia e a noite do céu soviético".

Cansado do subterrâneo, peguei a linha Butovskaya que circula majoritariamente a céu aberto, mas o encanto era outro: trens novos, estações aéreas, a ausência do ruído ensurdecedor do metal contra metal reboando no túnel. Senti falta da atmosfera noturna e claustrofóbica que envolve quem adentra o subsolo. Acredito, assim como Michel Maffesoli, que ao viver as zonas de sombra da cidade, instituímos uma utopia intersticial. O metrô me pareceu ideal, mesmo que vídeo-vigiado, para uma série de atividades pouco ortodoxas. Não soube distinguir os vendedores de atestados médicos, passaportes e drogas; os contratantes de mão de obra imigrante e os agentes da policia secreta; nem vi os surfistas de trem, mas tenho certeza que todos estavam lá.

Após duas semanas havia me familiarizado com o alfabeto cirílico, a comida local, o clima de outono, o mapa da cidade. Já era capaz de imaginar algumas das construções sob as quais passava quando dentro do metrô. Identifiquei-me com Marc Augé, que havia descrito essa sensação ao percorrer diariamente o metrô de Paris. Parei com as fotos, não por estar satisfeito com o resultado, mas porque os filmes haviam acabado. Passei parte do último dia sentado no cais da estação Novokuznetskaya, ouvindo Vetiver e assistindo ao movimento ritmado pela 
chegada dos trens. Lembrei da frase do poeta espanhol Antonio Machado "caminante no hay camino, se hace camino al andar" e peguei uma carona para São Petersburgo.

\section{REFERÊNCIAS:}

Augé, Marc. 1986. Un ethnologue dans le métro. Paris: Hachette.

Debord, Guy. 2006. Oeuvres. Paris: Editions Quarto Gallimard.

Machado, Antonio. 2006. Campos de Castilla. Madrid: Alianza Editorial.

Maffesoli, Michel. 2005. Éloge de la raison sensible. Paris: La table ronde.

Maffesoli, Michel. 1993. Aux creux des apparences : pour une éthique de l'esthétique. Paris: Le livre de poche.

Warnier, Jean-Pierre. 1999. Construire la Culture Matérielle. Paris: Presses Universitaires de France.

\section{Strolling through Moskovsky Metropoliten}

This narrative presents a point of view on the Moscow metro. Sharing individual perceptions of an underground collective experience, pictures, and text are remnants from the subjective feelings of a traveller in a subway atmosphere

Keyowords: photo-ethnography, urban drifting, metro, Russia. 